\title{
Meta-Analysis for Influence of Prestress Force on the Natural Frequency and Prestress Loss of Concrete Member
}

\author{
Hussam K. Risan and Rana I. K. Zaki
}

\begin{abstract}
The effect of prestress force value on the dynamic characteristic members dynamic characteristics been excessively argued among researchers till now. This study aims to perform a statistical method based on a meta-analysis investigating the influence of prestressing force on the first mode shape natural frequency of a prestressed reinforced concrete member and the related prestressing loss. The prior trials extracted from ScienceDirect, Scopus, Clarivate, and Research Gate electronic databases were used. The inclusion criteria encompass previous trials concerning experimental investigations of vibration frequencies as a function of prestressing force level with data capable of covert statistically to more meaningful information. Both analytical and numerical trials were excluded in this study. Twelve trials were matched with the objective of this review paper and satisfied the inclusion and exclusion criteria. A fixed-effects model type of metaanalysis was carried out based on the standardized mean difference. The present study shows a medium role for the prestress force in effecting the first vibration natural frequency mode. The total effect size is 0.93 standard deviations with 0.562 1.280 confident interval. The synthesized statistical analysis proves the efficiency of the meta-analysis method in predicting the influence of prestressing force on first eigenvalue frequency.
\end{abstract}

Key words - Natural Frequency; Prestress Force; Prestress Loss; Mode Shapes; Meta-Analysis.

\section{INTRODUCTION}

Nowadays, prestressing techniques are excessively applied for an extensive range of structural members, such as railway sleeper as a small member to long-span bridge as a large member. The damage detection throughout structural identification procedures, especially in infrastructures, is considered a demand tool since they can catch the structural deficiencies and reduce the collapse risk. These procedures can also optimize the limited available resources for the maintenance throughout, specifying a priority list of the damaged structures. Nonetheless, the reliability of these procedures is significantly affected by several parameters, especially the material type employed for the structure construction. It is known, accurate estimations of the dynamic character can be achieved for steel structures compared with concrete ones. The steel structure is mainly influenced by a small number of uncertainties (temperature variation, external support type, and non-structural masses), which is approximately be accepted for the service level modal analysis. Where in this level, the geometrical properties are

Submitted on August 25, 2021

Published on Febuary 28, 2022.

Hussam K. Risan, Al-Nahrain University, Iraq.

(e-mail: dr.hussamrisan@gmail.com) well defined. On the obverse, both reinforced and prestressed concrete members, besides the uncertainties show by steel structures, the nonlinear behavior in compression and tension due to crushing and cracking affects both position and amount of reinforcing rebar prestressing steel, prestressing profile, and finally prestressing force level.

In general, the effective state of prestressing force is considered a primary measure for prestressed reinforced concrete members' safety based on the serviceability level [1]. Indeed, the benefit of prestressing force in any structural prestressed concrete members is to control the deflection and cracking in addition to the primary function of partially counterbalance the dead and live loads. As an outcome, too much prestressing loss occurs, especially in standing aging structures, and may break prestressed concrete members' overall performance. Thus, it becomes necessary to attained tools or methods able to predict the actual loss in prestressing. Despite several ways based on sound and optical bases physics [2], [3], dynamic testing methods have been demonstrated to be fast and economical for evaluating structural integrity and reliability [4]. In addition to that, so far, the relationship between prestressed concrete members' dynamic characteristics with the prestressed force has come into the picture. The scientific dispute is still outstanding. In conjunction, significant experimental investigations have been performed to study the prestressed force value's influence on the prestressed members' natural frequency with no definitive evidence to emphasize this behavior.

This systematic review's objective through meta-analysis is to make a statistical decision on the effects of prestressing force on prestressed concrete members' natural frequency and associated prestressing loss. At first, some theoretical analyses are reviewed for illustration purposes only. In the second stage, statistical synthesis of the results of series experimental investigation is conducted. The third stage is implemented after defining the inclusion and exclusion criteria, developing the search strategy, and locating studies. Finally, the selected experimental studies data are extracted after assessing each study quality. In this final step, studies results are statically analyzed and interpreted by the metaanalysis technique.

Rana I. K. Zaki, Al-Nahrain University, Iraq. (e-mail: rana.i.zaki@ ${ }^{\circledR}$ ahrainuniv.edu.iq) 


\section{METHOD}

\section{A. Adopted Search Criteria}

Prior relevant trails interested in the influence of prestressing force on the prestressed concrete members' dynamic characteristics and associated prestressing loss were picked up from searching literature in ScienceDirect, Scopus, Clarivate, and Research Gate repositories. Trails were looked out based on Boolean combinations based on specific keywords such as natural frequency and (prestress force level or prestressing loss). Prestress force magnitude and (dynamic characteristics or dynamic properties or modal analysis or free vibration).

\section{B. Adopted Inclusion and Exclusion Concept}

Papers included in the original journal written in English language.

Papers dealt with prestressed reinforced concrete members, beams, or other structural elements.

Studies in which the subjects were included experimental works directly or indirectly and must cover the relationship between the natural frequencies as a function of the prestress force level of prestressed concrete members.

Articles included any range of prestress force levels.

Groups' statistics in clear and complete data-capable for comparison. Dynamic characteristics mean and standard deviation for the first mode.

Articles were dismissed if they were interested in analytical or theoretical background only. Further, the exclusion criteria eliminated other concrete material types. The inclusion search criteria assumed each study of the natural frequency without prestress force was named control while with any prestress force value as treated.

\section{META-ANALYSIS BACKGROUND}

To achieve any combined analysis as in the meta-analysis procedure, it must first find the effective size for an individual study and its variance based on the control and treatment data. In general, the effective size can be simulated either in the response ratio or in the mean difference. The mean difference is classified as either the mean raw difference or the mean standardized difference. In most engineering applications, the mean difference is usually used as a measure for the effective size. If studies experimental results are reported on an identical scale, the mean raw difference can be used directly. Otherwise, if different scales are implemented using different testing laboratory machines, the mean standardized difference will be dominant. The later mean difference based on a fixed-effects model is applied in this systematic review. The equation of the effective size (ES) for each study setup on mean standardized difference based on control and treated means is given as (5):

$$
E S_{i}=\frac{\left|\bar{X}_{1}-\bar{X}_{2}\right|}{S_{\text {pooled }}}
$$

$\bar{X}_{1}, \quad \bar{X}_{2}$ are the average in the two groups (control group without prestress force and the treated one with prestress force). The average (pooled) standard deviation based on different values of both the samples sizes and standard deviations is given as (5):

$$
S_{\text {pooled }}=\sqrt{\frac{\left(n_{1}-1\right) S_{1}^{2}+\left(n_{2}-1\right) S_{2}^{2}}{n_{1}+n_{2}-2}}
$$

$n_{1}, S_{1}$ and $n_{2}, S_{2}$ are referring to the size of the samples and standard deviations in control and treated groups, respectively. Knowing that the sample standard deviations may have different values despite the population's standard deviations are equal. For this reason and to get a more accurate value for the effective size variance for each study, the following approximate equation will be used in this paper as (6):

$$
V_{E S_{i}}=\frac{n_{1}+n_{2}}{n_{1} n_{2}}+\frac{E S^{2}}{2\left(n_{1}+n_{2}\right)}
$$

So, the standard error of the effective size for each trial can be defined as:

$$
S E_{E S_{i}}=\sqrt{V_{E S_{i}}}
$$

The inverse of each study's effective size variance is expressed as the weight of this study $w_{i}$. Based on that, the variance of the summary effective size $V_{T E S}$ of all studies can be defined as (6):

$$
V_{T E S}=\frac{1}{\sum w_{i}}
$$

Hence, the standard error of the total effective size is given easily by:

$$
S E_{T}=\sqrt{V_{T E S}}
$$

Moreover, the summary effective size value $E S_{T}$ for combined studies can be defined as:

$$
E S_{T}=\frac{\sum w_{i} E S_{i}}{\sum w_{i}}
$$

The $95 \%$ lower limit $L L$ and upper limit $U L$ of the confidence interval can be found based on the normality distributed assumption of the effective size as:

$$
\begin{aligned}
& L L=E S-1.96 \times S E_{E S} \\
& U L=E S+1.96 \times S E_{E S}
\end{aligned}
$$

All the above equations can be drawn in one graph named the forest plot. This plot is considered a crown. The forest plot consists of a set of squares or circles, each shape corresponding to each study. The center of this shape represents the effect size for each study. Further, the weight of each study is expressed in the size of this shape. Extend of 
whiskers emerging from these shapes on both sides is marked as the lower and upper confidence intervals for each study.

\section{ATTEMPTS AND DISCUSSION}

The theoretical solution of the natural frequency of onedimensional non-prestressed member is obtainable in several Engineering books, such as [7]. On the other side, the theoretical analysis of prestressed members' natural frequency is seldom available in the textbooks. A prestressed member's natural frequency can be obtained by combining two structural parts, as shown in Fig.1. The first part is a compressed concrete member, while the second one is simply a tensioned cable. The literature gives the natural frequency of each part separately as a complete analytical solution. The equation of the first part that depicted the fundamental frequency of a simply supported member with axial force is [7]:

$$
\omega_{n}=\frac{n \pi}{L_{\text {member }}} \sqrt{\frac{1}{m_{\text {member }}}\left[E I\left(\frac{n \pi}{L}\right)^{2}-N\right]}
$$

Where $L_{\text {member }}$ is the member length, $m_{\text {member }}$ is the member's mass per unit length, EI is the member flexural rigidity, $\mathrm{N}$ is the axial compressive force, and $\mathrm{n}$ is the mode number. The equation of the second part that described the natural frequency of cable under tension is [8]:

$$
\omega_{n}=\frac{n \pi}{L_{\text {cable }}} \sqrt{\frac{T}{m_{\text {cable }}}}
$$

where $L_{\text {cable }}$ The designated cable's length $m_{\text {cable }}$ is the mass per unit length of the designated cable, and $\mathrm{T}$ is the tensile force magnitude. As the theoretical part concludes, using (9) shows that a compressed member's natural frequency decreases as the axial compressive force's value increases. Equation (10) reveals that the cable's natural frequency under tension increases by increasing the tensioned force. Therefore, the accurate modal analysis of a prestressed member that combines two substructures imposes an entire account of the two substructures [9], [10].

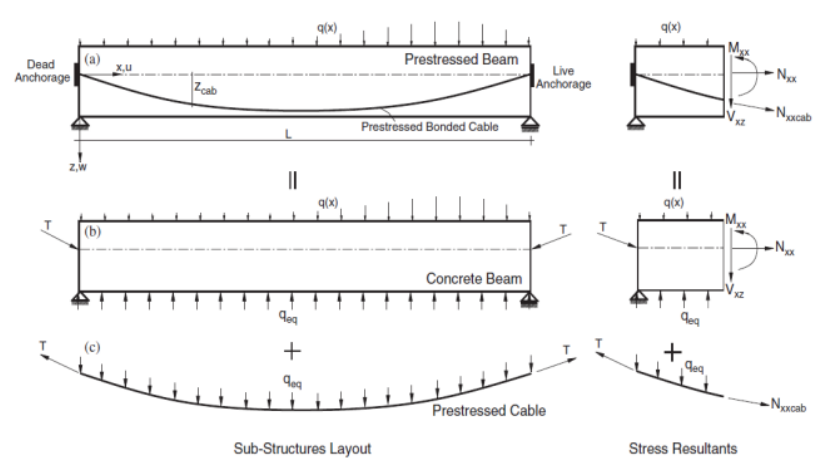

Fig. 1. Typical prestressed Member: (a) complete prestressed Member; (b) concrete member under compressive force; and (c) tensioned cable [10]

Several attempts based on either theoretical or numerical analyses were found in the literature [11]-[15]. Unfortunately, no precise, accurate, rational, and rigorous solution exist. For this reason, this systematic review is based on only experimental trials. Even that, there are many conflicts in the experimental investigation of this topic. How the prestressed force influences the natural frequency of prestressed concrete members? Some trials concluded that the natural frequency decreases with the increasing prestressed force-other said contrast of that.

In contrast, several trials confirmed that the prestressed force does not influence the natural frequency. Twelve trials were selected based on inclusion criteria specified in the method section above and the first mode natural frequencies' raw data for both controls. They treated the group, as shown

\begin{tabular}{|c|c|c|c|c|c|c|c|c|}
\hline \multirow[b]{2}{*}{$\#$} & \multirow[b]{2}{*}{ Study } & \multirow[b]{2}{*}{$\begin{array}{c}\text { Prestress Force } \\
\text { Range kN }\end{array}$} & \multicolumn{3}{|c|}{ Control } & \multicolumn{3}{|c|}{ Treated } \\
\hline & & & $\begin{array}{c}\text { Mean } \\
\mathrm{Hz}\end{array}$ & $\begin{array}{l}\mathrm{SD} \\
\mathrm{Hz}\end{array}$ & $\mathrm{n} 1$ & $\begin{array}{c}\text { Mean } \\
\mathrm{Hz}\end{array}$ & $\begin{array}{l}\mathrm{SD} \\
\mathrm{Hz}\end{array}$ & $\mathrm{n} 2$ \\
\hline 1 & Kerr, 1976 & 10.0 to 35.0 & 39.30 & 0.10 & 3 & 39.31 & 0.01 & 9 \\
\hline 2 & Нор, 1991 & 40.0 to 280.0 & 12.18 & 0.32 & 3 & 12.70 & 0.46 & 12 \\
\hline 3 & Saiidi et al, 1994 & 26.7 to 131.3 & 11.41 & 0.76 & 3 & 14.00 & 0.76 & 14 \\
\hline 4 & Miyamoto et al, 2000 & 9.80 to 58.80 & 53.38 & 2.10 & 4 & 54.88 & 1.48 & 11 \\
\hline 5 & Lu and Law, 2006 & 66.60 to 71.70 & 23.21 & 5.56 & 3 & 23.39 & 5.56 & 16 \\
\hline 6 & Jang et al, 2010 & 146.0 to 523.0 & 07.57 & 0.22 & 3 & 08.58 & 0.22 & 10 \\
\hline 7 & Kim et al, 2010 & 39.2 to 117.6 & 22.62 & 0.16 & 2 & 23.40 & 0.26 & 5 \\
\hline 8 & Noble et al, 2014 & 20.0 to 200.0 & 68.06 & 1.12 & 3 & 69.09 & 1.12 & 10 \\
\hline 9 & Shi et al, 2014 & 30.0 to 171.7 & 37.55 & 0.12 & 3 & 37.77 & 0.12 & 12 \\
\hline 10 & Noble et al, 2015 & 20.0 to 200.0 & 70.50 & 4.24 & 2 & 69.80 & 3.85 & 20 \\
\hline 11 & Noh et al, 2015 & 272.0 to 1088.0 & 20.51 & 0.07 & 3 & 20.50 & 0.07 & 12 \\
\hline 12 & Noble et al, 2016 & 10.1 to 16.9 & 78.52 & 0.44 & 9 & 88.77 & 13.92 & 22 \\
\hline
\end{tabular}
in Table I.
One of the oldest articles on this subject had been written in 1976 by [16]. The author accomplished several experimental tests on centric tendon prestressed concrete cantilever beams. The author proved that the natural frequencies were not influenced by the prestressing force magnitude based on the findings. After few years later, [17] in 1991 recorded the dynamic behavior of several prestressed reinforced normal and lightweight concrete beams. The study monitored the effect of prestress force values on the fundamental frequency and damping of the beam. According to the results observed, the author deduced that the beam vibration frequency increasing when the degree of axial prestress force increases to a specific limit. After that limit, inverse relation was recorded. Similar experimental observations were reached by [18]. The author conducted 
experimentally prestressed reinforced concrete beams with prestress force levels varying from 0 to 0.5 times the concrete compressive strength. Unground concentric strand was used. Results proved an increase in the first mode vibration from $11.41 \mathrm{~Hz}$ with no prestress force to $15.07 \mathrm{~Hz}$ for the prestress force with the maximum value.

In 2000, the vibration analysis of external tendons prestressed beams was investigated by [19]. Based on their findings, the girder's natural frequency is affected by the prestress force. Lu and Law [20] in 2006 performed an experimental investigation of four meters of ungrouted concentric seven-wire straight strand reinforced concrete beams. The tests were conducted with and without prestress force. According to the result obtained, the authors recorded that the prestressing force's application increases the first three mode shapes slightly. Jang et al. [21], in 2010, tested six scaled post-tensioned bonded tendons prestressed concrete beams. The results indicated a significant increase in the first natural frequency due to the effect of prestress force. Kim et al. [22] in 2010 conducted experimental scaled prestressed reinforced concrete girders for different damage scenarios of tendon prestress loss. The applied external prestressed force had been gradually reduced to zero to stimulate the prestressing loss. The dynamic results recorded a reduction of the first four shape modes frequencies from the initial process to the final one through this unloading progress.

Noble et al. [23] in 2014 analyzed the impact hammer test for prestressed post-tensioned concrete beams at different levels of prestress force. The authors recommended an increase in the concrete beam's fundamental frequency due to the effect of prestress force. Shi et al. [24] in 2014 developed a method for prestressing force identification of prestressed reinforced concrete members with external tendons according to the measured frequencies. Based on findings, the authors proved that the concrete member's natural frequency is a function of the prestress force. Noble et al. [25] in 2015 described the dynamic impact testing results on damaged post-tensioned concrete beams. According to the results found, the authors concluded a slightly inverse relationship between the fundamental frequency of the prestressed reinforced concrete beam and the prestress force level. Noh et al. [26] in 2015 tested three prestressed reinforced concrete beams with several strand configurations. They concluded approximately that no strong effect in the presence of prestress force, and they observed a decrease in the natural frequency due to an increase in the prestressing steel force level.

Finally, [27] in 2016 tested nine post-tensioned concrete beams. Both static three points bending testing and dynamic testing were performed on all beams under consideration at various levels of post-tensioning force. The results were recorded ten times at three impact locations per each load level of eleven levels. Based on these extensive results, the authors concluded a direct relationship between the prestressed reinforced concrete beams' fundamental frequencies and the level of the prestress force applied in the prestressing process. The raw data are shown in Table I for the twelve trials are transferred based on [1]-[8] to information in terms of effective size, confident interval, and trial weights and illustrated in Table II. Also, Table II illustrates the summary effective size for the total of twelve trials with the lower and upper confidence intervals.

As a general summary, no complete agreement exists in the examined literature for the relation between the prestressed reinforced concrete member's vibration frequency and the prestress force level. Experimental findings often agree that there is an influence of the prestress force on the natural frequency of the prestressed concrete members. The accuracy of the dynamic devices plays an essential role in the sensitivity of the experimental recording results. The problem is so complicated due to many parameters such as prestress type, method, and level. Hence, theoretical models are unable to explain such phenomena. To study these topics in a clear and reliable picture, the authors have decided to use a combined statistical method, precisely the meta-analysis method, based on the literature's experimental findings. The combined analysis is performed in this study based on the standardized mean difference for the above twelve trials that satisfy the inclusion criteria specified in the method section above. The results regarding effect size, weight, and confidence interval with forest plot are drawn in Fig. 2. The plot shows the influence of prestressing force on the prestressed reinforced concrete member's first mode vibration frequency. This plot directly clarifies the variation in the trial's findings. The total grand effective size for the total trials is 0.93 , which lies in the medium effect. The confident interval of the summary effective size of the total grant trials is $0.562-1.280$.

TABLE II: BASIC INFORMATION

\begin{tabular}{cccccc}
\hline & \multirow{2}{*}{ Study } & Effective & \multicolumn{2}{c}{$\begin{array}{c}\text { Confident } \\
\text { Interval }\end{array}$} & \multirow{2}{*}{$\begin{array}{c}\text { Weight } \\
\text { Size }\end{array}$} \\
\cline { 4 - 5 } & & & LL & UL & \\
\hline 1 & Kerr,1976 [16] & 0.10 & -1.106 & 1.308 & $9 \%$ \\
2 & Hop,1991 [17] & 1.11 & -0.146 & 2.364 & $8 \%$ \\
3 & Saiidi et al,1994 [18] & 3.23 & 1.627 & 4.842 & $5 \%$ \\
4 & Miyamoto et al,2000 & 0.86 & -0.261 & 1.979 & $10 \%$ \\
5 & Lu and Law,2006 [20] & 0.03 & -1.147 & 1.209 & $9 \%$ \\
6 & Jang et al,2010 [21] & 4.27 & 2.237 & 6.304 & $3 \%$ \\
7 & Kim et al,2010 [22] & 2.70 & 0.723 & 4.676 & $3 \%$ \\
8 & Noble et al,2014 [23] & 0.86 & -0.389 & 2.100 & $8 \%$ \\
9 & Shi et al,2014 [24] & 1.73 & 0.384 & 3.067 & $7 \%$ \\
10 & Noble et al,2015 [25] & -0.17 & -1.573 & 1.225 & $7 \%$ \\
11 & Noh et al,2015 [26] & -0.13 & -1.326 & 1.057 & $9 \%$ \\
12 & Noble et al,2016 [27] & 0.84 & 0.059 & 1.626 & $21 \%$ \\
& Summary & 0.93 & 0.562 & 1.280 & $100 \%$ \\
\hline
\end{tabular}

\section{CONCLUSION}

The present systematic review investigation of the first mode frequency percentage change in prestressed reinforced concrete members under various prestressing forces that simulate prestressing loss in the strand has been carried out. The relation between the prestressed reinforced concrete members' natural frequencies with the prestress forces has been statistically calculated by the meta-analysis method. The proposed method's applicability has been based on effective size, weight, and confidence intervals of twelve experimental studies found in the literature according to inclusion and exclusion criteria. Based on the discussion of the results obtained by statistical simulation, the following conclusions can be made.

This investigation's statistical results demonstrate the effectiveness of detecting loss of prestressing force as a 
function of the natural freque ncy in $\mathrm{p}$ restressed reinforced concrete members by using a meta-analysis procedure.

The prestress force's medium effect on the first mode vibration fundamental frequency in prestressed reinforced concrete member. The summary effect size is 0.93 standard deviations with $0.562-1.280$ confident interval.

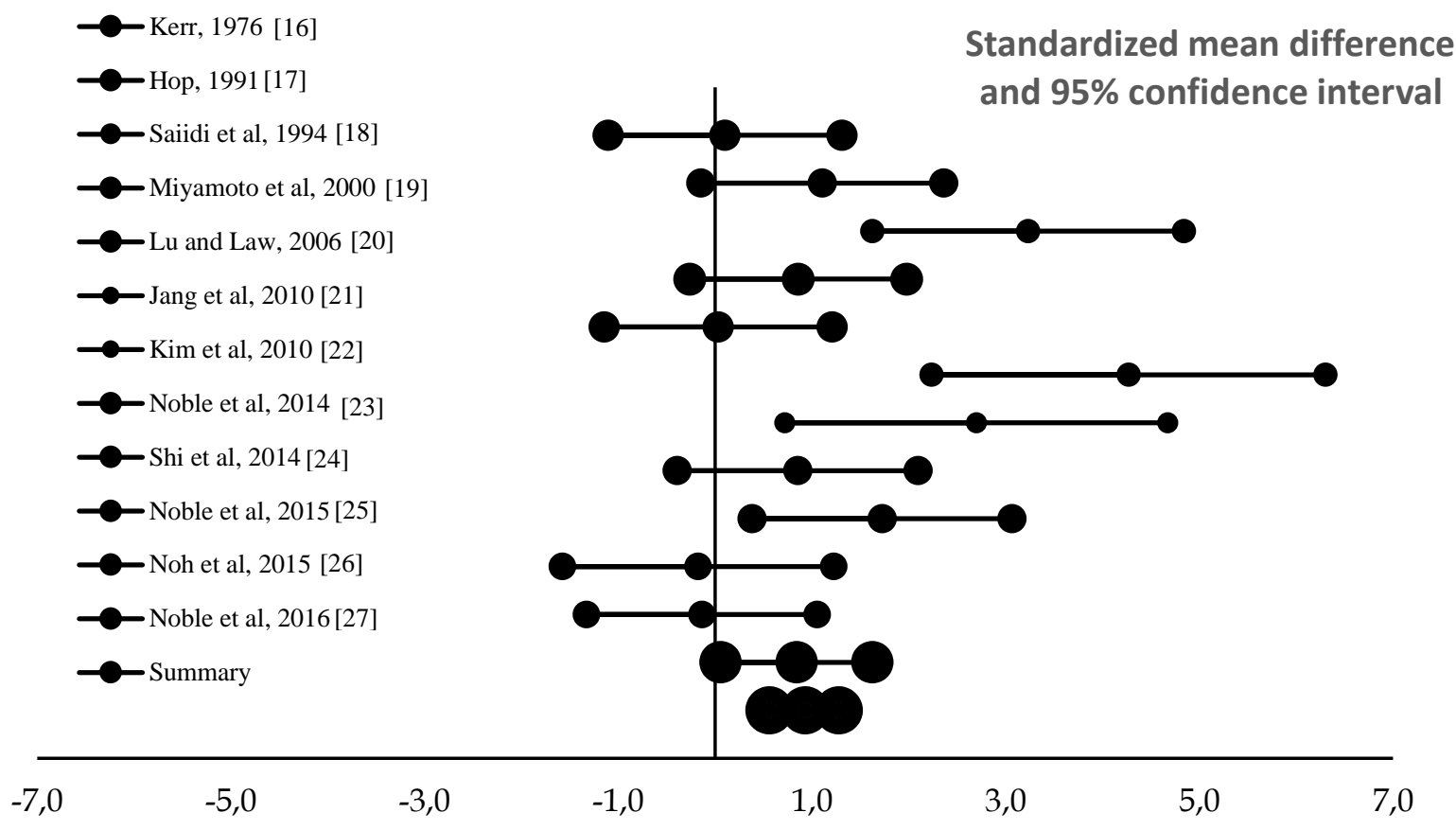

Fig. 2. Impact of Prestressing Force on the Vibration Frequency.

\section{ACKNOWLEDGMENT}

The authors thank everyone who helped us in completing this research, and also thank our educational institution, AlNahrain University, for providing the facilities for us.

\section{FUNDING}

Although there is no financial support for this research, we would like to thank our educational institution, which is AlNahrain University, for providing the facilities for us.

\section{CONFLICT OF INTEREST}

Authors declare that they do not have any conflict of interest.

\section{REFERENCES}

[1] Breccolotti M. and Materazzi A. Prestress losses and camber growth in wing-shaped structural members, PCI Journal, (2015), 60(1), 98-117.

[2] Bartoli I., Nucera C., Phillips R., Salamone S., Srivastava A., Di Scalea F., et.al. Stress monitoring in prestressing tendons for post-tensioned concrete structures by nonlinear ultrasonic guided waves. In Proceedings of the 7th international workshop on structural health monitoring, IWSHM 2009, Vol.2, pp.2155-2122.

[3] Lan C., Zhou Z. and Ou J. Full scale prestress loss monitoring of damaged rc structures using distributed optical fiber sensing technology. Sensors (Switzerland), 2012, 12 (5), 5380-5394.

[4] Salawu O. Detection of structural damage through changes in frequency: A review. Engineering Structures, 1997, 19 (9), 718-723.

[5] Tripodi T., Dattalo P. and Thyer B.A. Systematic Reviews and MetaAnalysis, Oxford University Press, Inc., New York; 2008.

[6] Borenstein M., Hedges L. V., Higgins J. P.T. and Rothstein H. R. Introduction to Meta-Analysis, John Wiley \& Sons, Ltd, United Kingdom; 2009.
[7] Timoshenko S., Young D.H. and Weaver W.J.R. Vibration Problems in Engineering, Wiley, New York; 1974.

[8] Irvine H.M. Cable Structures, The MIT Press, England;1981.

[9] Chan T.H.T. and Yung T.H. A theoretical study of force identification using prestressed concrete bridges, Engineering Structures, 2000, 22 (11) 1529-1537.

[10] Dallasta A. and Leoni G. Vibration of beams prestressed by internal frictionless cables, Journal of Sound and Vibration, 1999, 222 (1) 118.

[11] Law S.S. and Lu Z.R. Time domain responses of a prestressed beam and prestress identification, Journal of Sound and Vibration, 2005, 288 1011-1025, doi:10.1016/j.jsv.2005.01.045

[12] Hamed E and Frostig Y. Natural frequencies of bounded prestressed beams-prestress force effects, Journal of Sound and Vibration, 2006 , 295, 28-39, doi:10.1016 j.jsv.2005.11.032.

[13] Hao Li., Zhongrong Lv. and Jike Liu. Assessment of prestress force in bridges using structural dynamic responses under moving vehicles, Hindawi Publishing Cooperation, Mathematical Problems in Engineering, 2013, Article ID 435939, 9 pages, http://dx.doi.org/10.1155/2013/435939.

[14] Breccolotti M. On the evaluation of prestress loss in PRC beams by means of dynamic techniques, International Journal of Concrete Structures and Materials, 2018, doi:10.1186/s40069-018-0237-8.

[15] Kovalovs A., Akishin P. and Chate A. Detection prestress loss in prestressed concrete slab using modal analysis, IOP Conf. Series: Material Science and Engineering, 2019, 471, 102015 doi:10.1088/1757-899X/471/10/102015.

[16] Kerr A. D. On the dynamic response of a prestressed beam, Journal of Sound and Vibration, 1976, 49(4), 569-573.

[17] Hop T. The effect of degree of prestressing and age of concrete beams on frequency and damping of their free vibration, Materials and structures, 1991, 24(3), 210-220.

[18] Saiidi M., Douglas B. and Feng S. Prestress force effect on vibration frequency of concrete bridges, Journal of Structural Engineering (United States), 1994, 120(7), 2233-2241.

[19] Miyamoto A., Tei K., Nakamura H. and Bull J. Behavior of prestressed beam strengthened with external tendons, Journal of Structural Engineering, 2000, 126(9), 1033-1044.

[20] Lu Z. and Law S. Identification of prestress force from measured structural responses, Mechanical Systems and Signal Processing, 2006, 20(8), 2186-2199.

[21] Jang J.-B., Lee H.-P., Hwang K.-M., and Song Y.-C. Prediction of prestress force on grouted tendons by experimental modal analysis, In Proceedings of the IMAC-XXVIII, 2010. 
[22] Kim J.-T., Park J.-H., Hong D.-S. and Park W.-S. Hybrid health monitoring of prestressed concrete girder bridges by sequential vibration-impedance approaches, Engineering Structures, 2010, 32(1), $115-128$.

[23] Noble D., Nogal M., O'Connor AJ. And Pakrahi V. The effect of prestress force magnitude on the natural bending frequencies of prestressed concrete structure, 23rd Australasian Conference on the Mechanics of Structures and Materials (ACMSM23). Byron Bay, Australia, 9-12 December 2014, S.T. Smith (Ed.).

[24] Shi L., He H. and Yan W. Prestress force identification for externally prestressed concrete beam based on frequency equation and measured frequencies, Hindawi Publishing Corporation, Mathematical Problems in Engineering, 2014, Article I.D. 840937, 13 pages, http//dx.doi.org/10.1155/2014/840937.

[25] Noble D., Nogal M., O'Connor AJ. And Pakrahi V. The effect of posttensioning force magnitude and eccentricity on the natural bending frequency of cracked post-tensioned concrete beams, 11th International Conference on Damage Assessment of Structures (DAMAS 2015), Journal of Physics: Conference Series, 2015, 628, 012047, doi:10.1088/1742-6596/628/1/012047.

[26] Noh, M.-H., Seong, T.-R., Lee, J., \& Park, K.-S. Experimental investigation of dynamic behavior of prestressed girders with internal tendons. International Journal of Steel Structures, 2015, 15(2), 401414.

[27] Noble D., Nogal M., O'Connor AJ. And Pakrahi V. The effect of prestress force magnitude on the natural bending frequencies of uncracked prestressed concrete beams, Journal of Sound and Vibration, 2016, 365, 22-44.

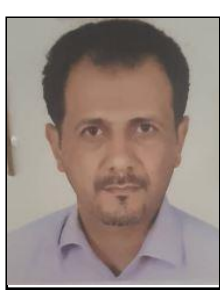

Hussam K. Risan Born in Basra, Iraq, a PhD doctorate in civil engineering from Al-Nahrain University, Baghdad, Iraq, in 2013 had been obtained, with a specialization in structural engineering.

He is currently teaching with the title of Assistant Professor at Al-Nahrain University - College of Engineering, Civil Engineering Department. He teaches many subjects for undergraduate and postgraduate students and has an important and large group of research that can be accessed through the available electronic search engines.

Assist Prof. Dr. Risan has a member of the Iraqi Engineers Syndicate and a faculty member at Al-Nahrain University and other educational institutes. 